\title{
The Use of Thermoelectric Generators With Home Stoves
}

\author{
Maciej Żołądek ${ }^{l, *}$, Karolina Papis ${ }^{l}$, Jakub Kuś ${ }^{l}$, Michat Zając ${ }^{l}$, Rafat Figaj ${ }^{l}$, Kyrylo Rudykh ${ }^{l}$ \\ ${ }^{1}$ AGH University of Science and Technology, Faculty of Energy and Fuels, Department of Sustainable Energy Development
}

\begin{abstract}
One of waste heat recovery technologies are thermoelectric generators, which allow direct conversion heat to energy. In the face of shrinking fossil fuels resources, simultaneous increase of global energy demand and level of pollution it is becoming more and more important to introduce technologies enabling fullest utilization of fuels. In the paper, tests of water and air cooled thermoelectric generators mounted on the stove were described. Problems that occurred while operation of the system and its solutions were presented. Analysis of factors influencing incineration process, therefore affecting produced electrical energy was carried out. Power and voltage-current characteristics of generators were drawn up. A possible electrical energy yield in conditions described in this paper was also estimated.
\end{abstract}

\section{Introduction}

Thermoelectric generators are devices whose use is possible, for example, to recover heat lost from gases from combustion processes. Energy can be recovered from a number of processes - from small scale heating appliances, through combustion vehicles to steelworks or widely understood heavy industry. The advantages of thermoelectric generators (TEG), such as direct energy conversion, no moving parts, long life cycle, scalability or noiseless operation, make it possible to use it in numerous, extreme applications, such as powering cosmic probes (Apollo, Voyager, Pioneer, Curiosity, etc.), by using the heat from the radioactive decay of plutonium 238. Lighthouses distant from inhabited areas in Russia operated on a similar principle [1]. Nowadays, thermoelectric generators are usually used to supply electricity to remote areas using the heat of natural gas combustion [2]. The car industry is probably the most attractive sector for using TEGs. In diesel engines, about $30 \%$ of fuel energy is lost in the exhaust. Recycling even $3 \%$ of this energy allows to recover up to $900 \mathrm{~W}$ of electricity, which is associated with a reduction in $\mathrm{CO} 2$ emissions by $12-14 \mathrm{~g} / \mathrm{km} \mathrm{CO} 2$. The solution presented by Scania in 2015 with the heavy duty truck enabled to recover $775 \mathrm{~W}$ of electricity [3]. Research carried out by Boeing Research and Technology has shown that using TEGs for jet engines and helicopter turbines reduces fuel consumption about $0.5 \%$, which, in the case of full commercialization of the solution will reduce monthly operational cost by 12 million dollars [4]. In recent years, many materials with thermoelectric properties, differing in maximum temperature and temperature gradient at maximum power point have been created. Another novelty are printed polymer cells with a structure that allows them to be bent and adapted to the shape of heat source [4].
The idea of a microcogeneration system based on wood stove and a thermoelectric generator is shown in figure 1.

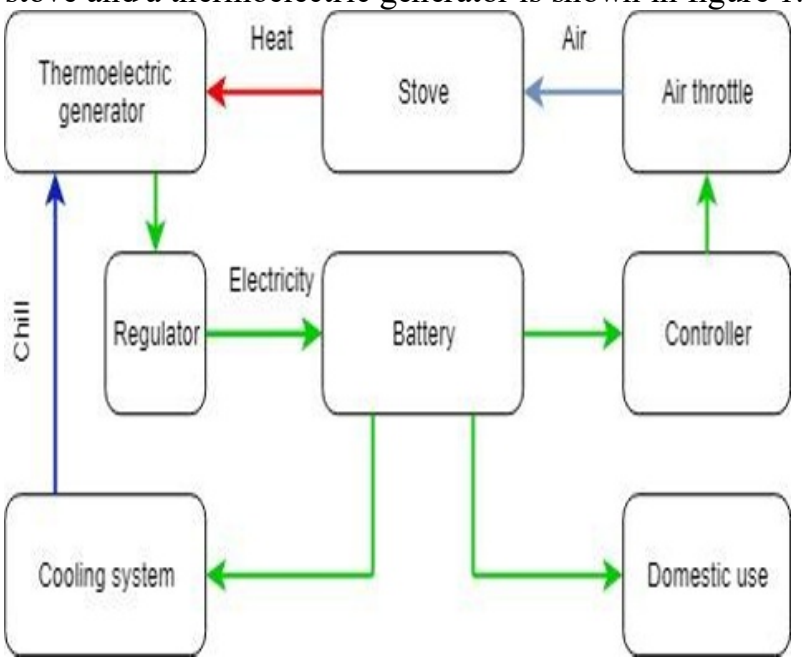

Fig. 1. Schematic diagram of the system with a fireplace and a thermoelectric generator

The proposed system consists of a thermoelectric generator, a voltage regulator, a battery and battery charge controller and a controller of air throttle operation. The generated energy is consumed for the purpose of controlling the combustion process, i.e. the controller and the servomotor controlling the inflow of air to the combustion chamber, additionally the cooling of the TEGs cold side is supplied. The energy surplus can be used, for example, to supply a circulating pump or circulating domestic installation.

The literature shows a few examples of the installation of thermoelectric generators at stoves based on solid fuels. Nuwayhid et al. presented a system generating electricity using thermoelectrics at the domestic stove, which was cooled by natural convection. The maximum power reached is $4.2 \mathrm{~W}$ using a single module [5]. In a similar analysis, Champier reached the final power of $7.6 \mathrm{~W}[6]$. 
Another study, done by Rindale et al. concerned a system with forced water cooling. In this case, it was possible to obtain $10 \mathrm{~W}$ of power with an electric constant source of heat [7]. Figure 2 shows the scheme of operation of exemplary thermoelectric module. Heat is provided to the hot side of the module, which is made of ceramics, such as cold side. The layer between hot and cold side of the generator consists of an array of n- and p-type bismuth telluride semiconductors.

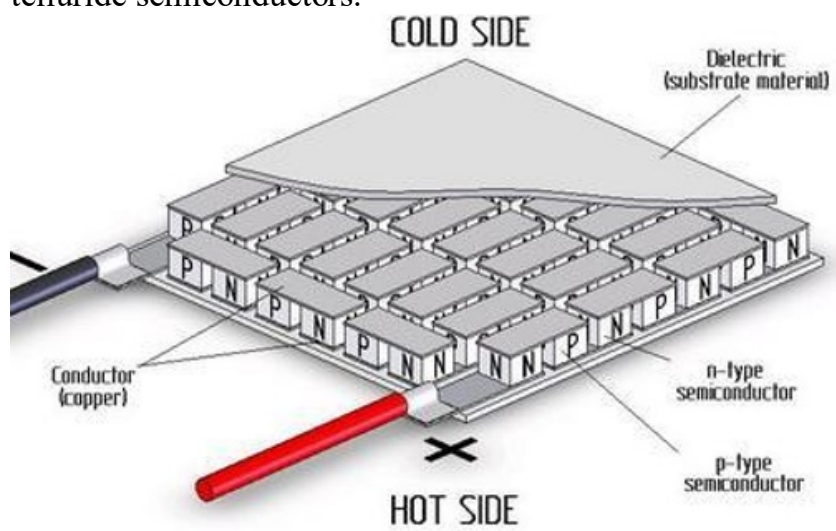

Fig. 2. Exemplary thermoelectric module

\section{Experimental Rig}

As a source of heat, a domestic, steel stove fired with seasoned wood with the moisture content of $20 \%$ was used. The thermal power of the device was in the range of $8-16 \mathrm{~kW}$. The thermal efficiency of the device is declared as $81 \%$. The internal walls are lined with a layer of fire clay aimed at stabilizing the conditions of the combustion process. Two types of thermoelectric generators mounted on the flat surface of the stove were used. In the first case, a TEG with declared output power of $45 \mathrm{~W}$ was used, consisting of 6 thermoelectric modules connected in series, air-cooled from two fans. The second generator, which construction is shown in figure 3 with a declared power $100 \mathrm{~W}$, built of 8 modules connected in series, is cooled with running water at a temperature of about 20 Celsius degrees.

Construction of the generator is highly imperfect, because of leaving empty space in nearly half of generators surface. Both hot and cold side of the generator was covered with thermally conductive paste before the study. Before conducing analyses of generators operation, the temperature levels reached on the stove were checked. Analysis taken with the use of infrared camera is shown in the figure 4. Most parts of the stove surface have temperature at the range between 300 and $400{ }^{\circ} \mathrm{C}$, except the central part of the stove, where temperature exceeds $500{ }^{\circ} \mathrm{C}$.

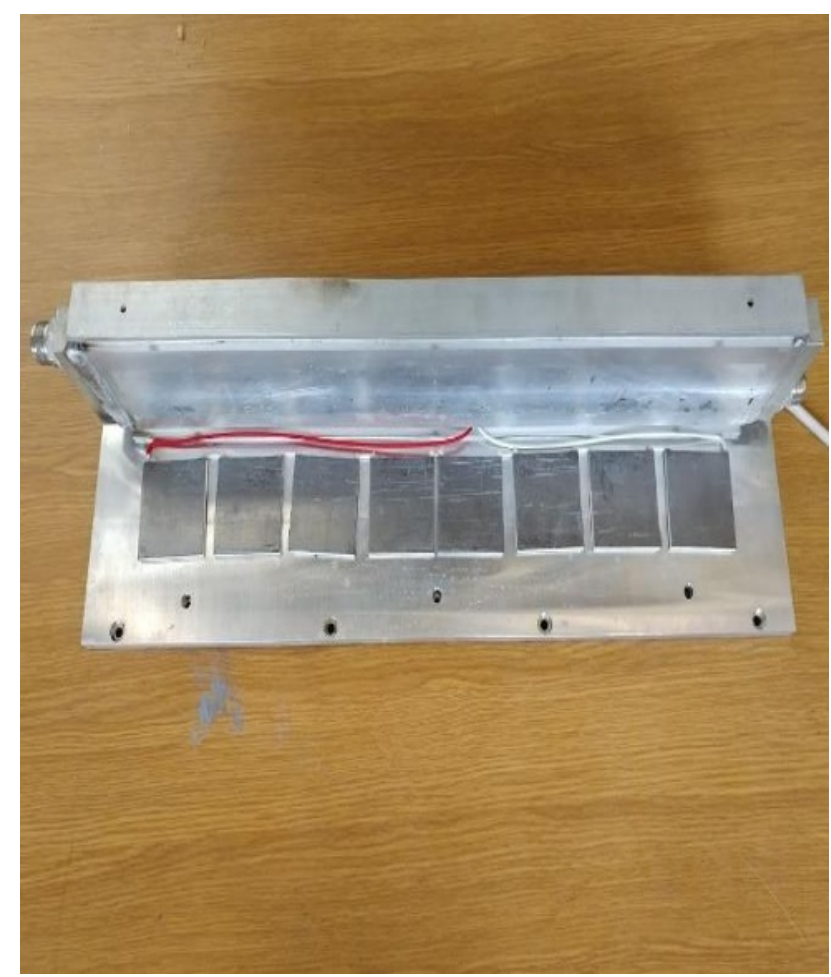

Fig. 3. Thermoelectric generator cooled with water

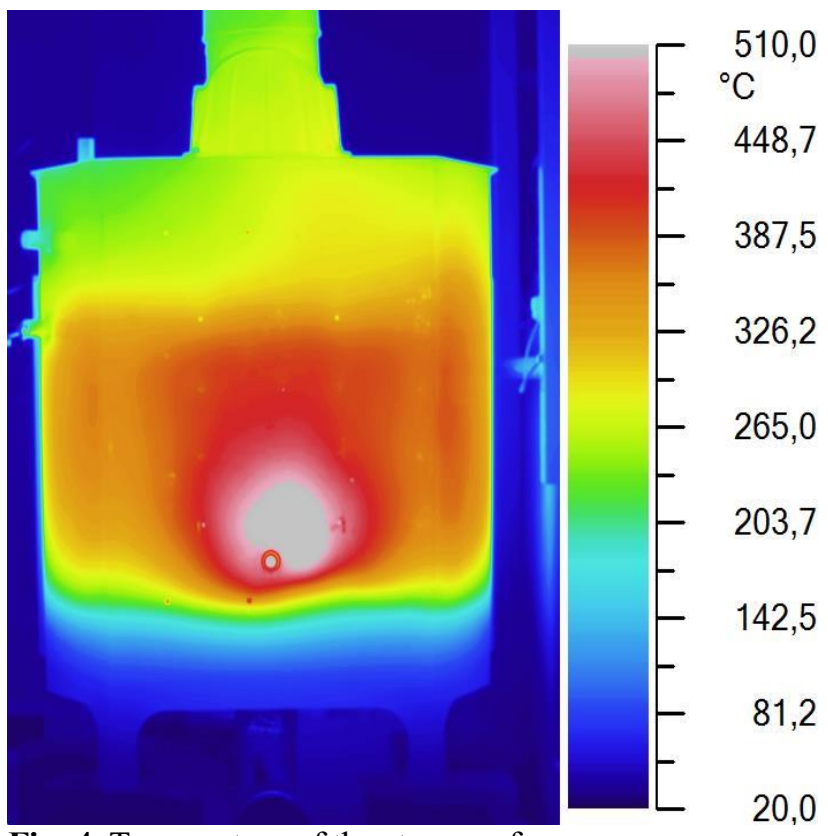

Fig. 4. Temperature of the stove surface

Based on this analysis, generators were mounted on the parts with highest and most stable temperaturę. Mounting of both generators on the stove surface is shown in figure 5. 


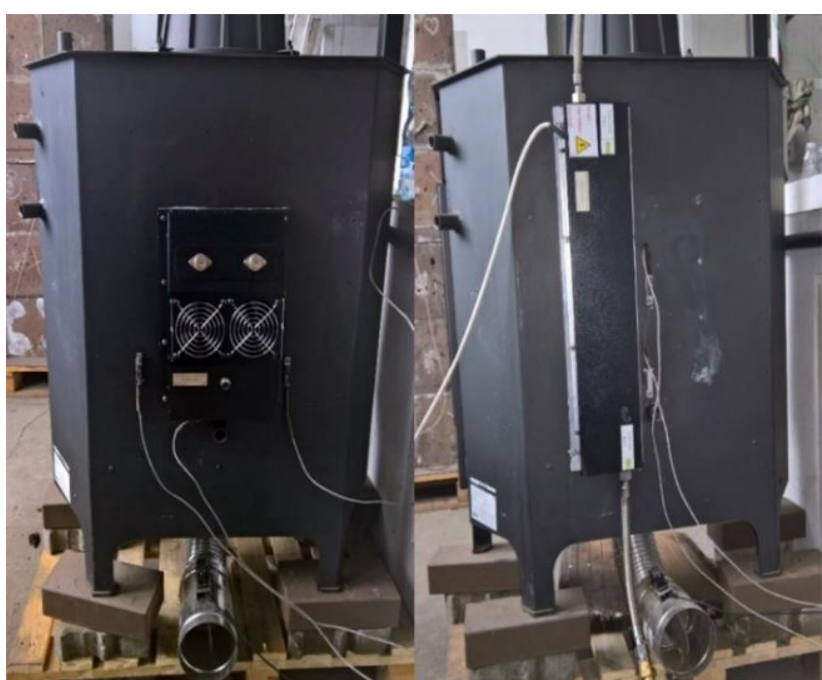

Fig. 5. Installation with air-cooled thermoelectric (left) and water-cooled thermoelectric (right)

The measuring system consisted of the WAGO PFC200 PLC controller connected to three resistive temperature sensors located on the stove wall and three thermocouples measuring the temperature inside the combustion chamber. Air throttle also connected with the controller was able to dose air supply to the combustion chamber. The electrical parameters of the system were tested using an electronic load. Parameters of the load was:

-Input Voltage in range from 0 to $80 \mathrm{~V}$,

-Input Current in range from 0 to $40 \mathrm{~A}$,

-Input Power in range from 0 to $400 \mathrm{~W}$,

-Voltage Accuracy $\pm 0.1 \%+10 \mathrm{mV}$,

-Current Accuracy in range from 0 to $4 \mathrm{~A}: \pm 0.1 \%$ $+5 \mathrm{~mA}$,

-Current Accuracy in range from 0 to $40 \mathrm{~A}: \pm 0.1 \%$ $+10 \mathrm{~mA}$,

-Maximum Resolution of Voltage: $1 \mathrm{mV}$,

-Maximum Resolution of Current: 0.1mA.

\section{Results and discussion}

The operating parameters of the generators (voltage, current and generated power) varied depending on the temperature of the hot and cold side of the modules. In the study it was not possible to measure the temperature of the cold side, it was calculated based on the Seebeck coefficients of the modules and estimated in the case of an air-cooled generator at 140 Celsius degrees and watercooled at 85 Celsius degrees. Temperature distribution on the stove surface after mounting air cooled generator is shown in figure 6 .

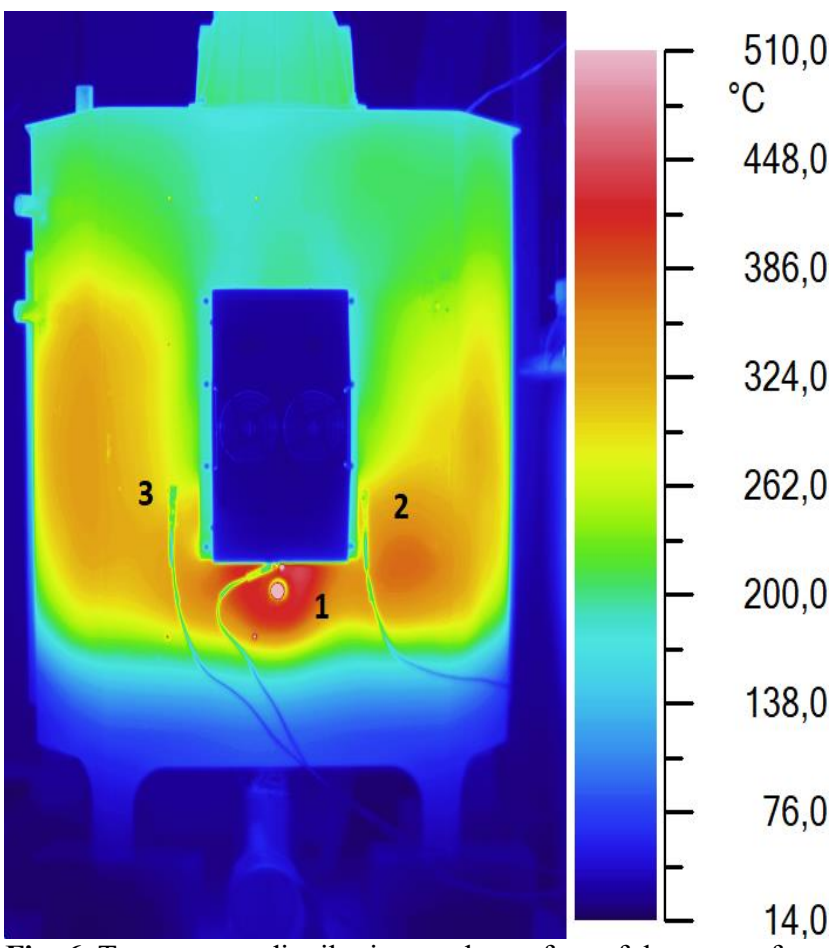

Fig. 6. Temperature distribution on the surface of the stove after mounting air cooled generator

The temperature of the hot side was measured by a resistance sensor and depending on its value characteristics IV and PV were determined. In the case of an air-cooled generator, it was shown that the shortcircuit current value is lower than $5 \mathrm{~A}$, while the open circuit value does not exceed $17 \mathrm{~V}$ in the most favourable case. Power at MPP reached $18.1 \mathrm{~W}$, which is $40,2 \%$ of the power declared by the manufacturer at the level of 45 W. The difference is due to the uneven distribution of temperature on the stove wall and the sub-optimal temperature difference between hot and cold side of the modules. Tests made for an air-cooled generator are shown in figure 7 and 8

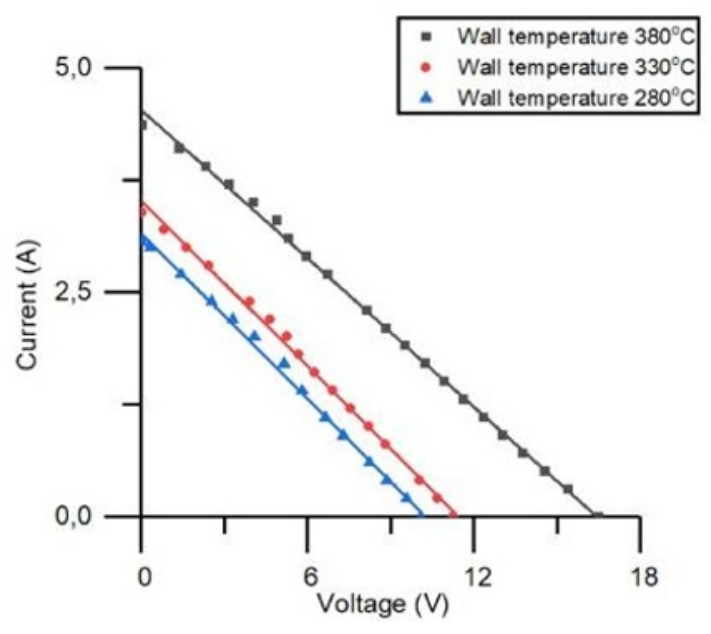

Fig. 7. I-U characteristics of the air cooled generator 


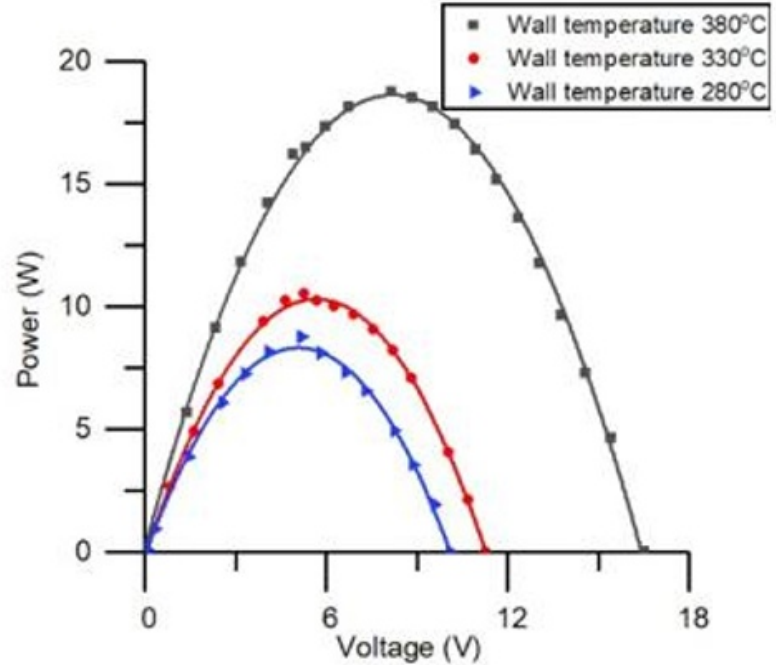

Fig. 8. P-U characteristics of the air cooled generator

The short-circuit current in the case of a water-cooled generator slightly exceed $5 \mathrm{~A}$, while the open circuit voltage did not exceed $24.5 \mathrm{~V}$. The power in MPP is 30.7 $\mathrm{W}$, which is $30.7 \%$ of the declared power of the device. This fact may result from the generator's sub-optimal attachment - it does not fully coincide with the hottest area of the stove wall due to its size and shape. Temperature of the stove surface after mounting the generator is shown in figure 9 .

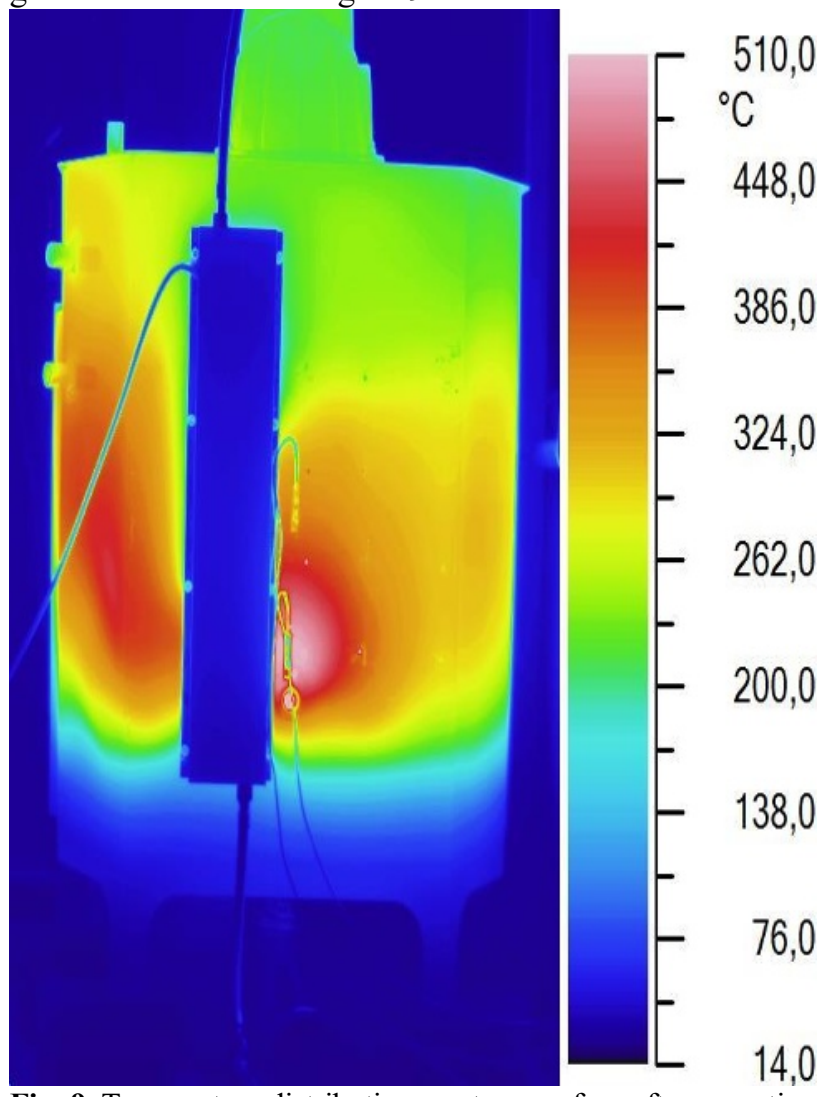

Fig. 9. Temperature distribution on stove surface after mounting water cooled generator

Electrical parameters of the generator are shown on figures 10 and 11 .

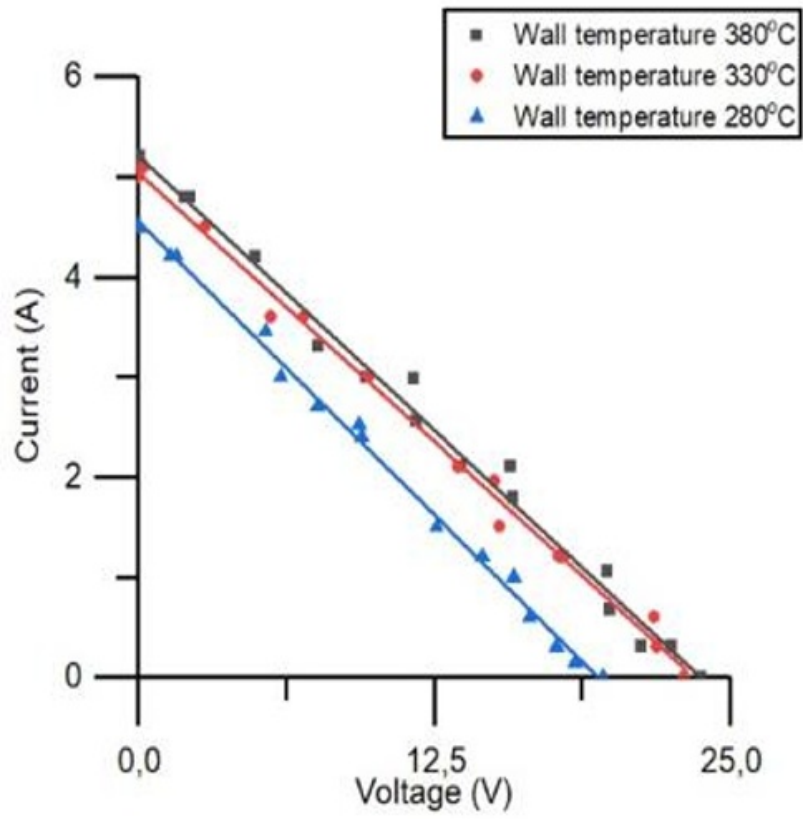

Fig. 10. I-U characteristics of the water cooled generator

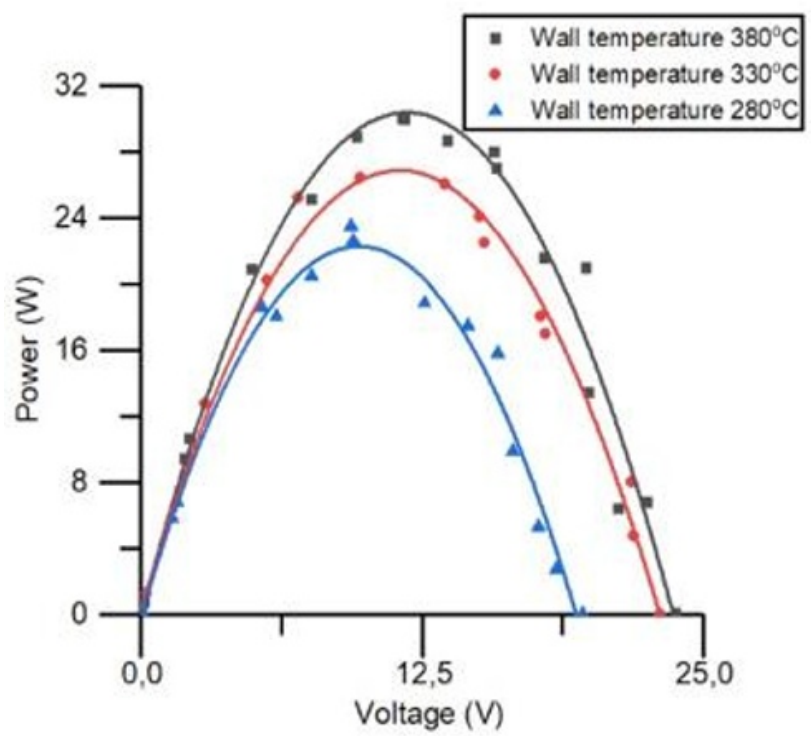

Fig. 11. P-U characteristics of the water cooled generator

\section{Conclusions}

Thermoelectric generators may be a promising way to generate electricity, however, it is necessary to take care of the specific operating conditions of designed installations. The most important one is to ensure the appropriate temperature gradient between the hot and cold side of the of the modules, which allows to maximize their efficiency. The low power of devices and relatively large investment costs are balanced by numerous advantages, including reliability and, above all, independence of the cogeneration systems based on thermoelectrics. This fact can make them an important element of the energy system in installations without permanent power supply from the network. The author's experience shows that manufacturers of thermal devices are interested in designing installations that are able to supply their own needs, which makes the thermoelectric 
generators an element of the market that is worth implementing. While in the analysed case the obtained power, for an air-cooled generator, $18.1 \mathrm{~W}(3 \mathrm{~W}$ per single module), and in the case of a water-cooled generator $30,7 \mathrm{~W}(3.9 \mathrm{~W}$ per single module), it is possible to design generators with a better cold side cooling system, which will maximize the achieved values.

\section{Acknowledgements}

The work has been completed as a part of the statutory activities of the Faculty of Energy and Fuels at the AGH UST in Krakow "Studies concerning the conditions of sustainable energy development". Experimental studies have been carried out in the Center of Energy of the AGH University of Science and Technology in Krakow.
1. Alimov. Radioisotope Thermoelectric Generators Bellona n.d. [accessed September 24, 2015].

2. Welcome to Gentherm Global Power Technologies | Gentherm Global Power Technologies n.d. [accessed September 24, 2015].

3. F. Frobenius, G. Gaiser, U. Rusche, B. Weller. J Electron Mater 8 (2015)

4. D. Champier,, En. Conv. Man., 140 (2017)

5. R.Y. Nuwayhid,, A. Shihadeh, N. Ghaddar., En. Conv. Man, 46, (2005)

6. D. Champier, J.P. Bédécarrats, T. Kousksou, M. Rivaletto, F. Strub, P. Pignolet, Energy, 36, 3, (2011)

7. G.F. Rinalde, L.G. Juanico, E. Taglialavore, S. Gortari, M.G. Molina, Int J Hydrogen Energ, 35, 11 (2010)

\section{References}

